\title{
The physical, emotional and behavioral symptoms of health problems among employees before and during the COVID-19 epidemic
}

\author{
Maja Rožman and Polona Tominc \\ Faculty of Economics and Business, University of Maribor, Maribor, Slovenia
}

Received 13 October 2020

Revised 7 April 2021

8 June 2021

Accepted 8 June 2021

\begin{abstract}
Purpose - The coronavirus disease 2019 (COVID-19) epidemic has caused stress for everyone and impacted the lives of people globally. Such stress increases troubles for the employees. Therefore, the aim of the paper is to identify symptoms of health problems that employees face during the COVID-19 epidemic. Also, the aim of the paper is to examine if there are statistically significant differences in the physical, emotional and behavioral symptoms of health problems among employees before the COVID-19 epidemic and employees during the COVID-19 epidemic.

Design/methodology/approach - The research is based on a survey of 950 employees in Slovenian companies. The factor analysis and the $t$-test for two independent samples were used to test the hypotheses of the research.

Findings - The results show that physical, emotional and behavioral symptoms of health problems of employees during the COVID-19 epidemic are intensified as compared to the before COVID-19 epidemic era. Originality/value - The results highlight the measures with which companies can reduce the problem of different symptoms of employees during the COVID-19 epidemic. The results can be useful for employers and for managers who want to create an adequate working environment for employees during the COVID-19 epidemic.
\end{abstract}

Keywords Physical symptoms, Emotional symptoms, Behavioral symptoms, COVID-19 epidemic

Paper type Research paper

\section{Introduction}

The coronavirus disease 2019 (COVID-19) epidemic, in combination with the strict health protection and containment measures, represents a significant negative shock for economic activity in Slovenia, other European countries and globally (Institute of Macroeconomic Analysis and Development, 2020). The World Health Organization on March 11th, 2020, declared a pandemic of the highly transmissible COVID-19 (WHO, 2020a, b). Since then, the rapid worldwide outbreak of the novel coronavirus has triggered an alarming global health crisis. Many countries' governments have taken measures dramatically affecting the daily life of society (Kraus et al., 2020). These measures not only affect the populations' daily life but have caused significant economic consequences in economies around the world (Baker et al., 2020). Governments have set severe restrictions on various industries, mandated social distancing and health protection policies, and even locked down nonessential businesses in many countries, triggering simultaneous demand as well as supply-side issues (del RioChanona et al., 2020). Many industries face supply-side issues, as governments curtail the activities of nonessential industries, and employees are confined to their homes. Businesses

(C) Maja Rožman and Polona Tominc. Published by Emerald Publishing Limited. This article is published under the Creative Commons Attribution (CC BY 4.0) licence. Anyone may reproduce, distribute, translate and create derivative works of this article (for both commercial and non-commercial purposes), subject to full attribution to the original publication and authors. The full terms of this licence may be seen at http://creativecommons.org/licences/by/4.0/legalcode

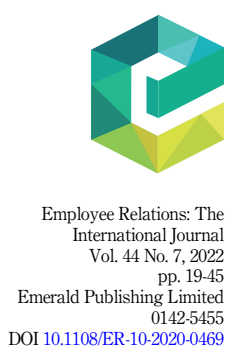


ER

44,7

need to contend with several challenges, including the implementation of required health protection measures, reduced production and demand and supply chain disruptions (Kraus et al., 2020). As the spread of the COVID-19 epidemic and the time of its containment are a great unknown, high uncertainty remains, and there is a risk that the period of severely paralyzed economic activity will last longer than assumed (Institute of Macroeconomic Analysis and Development, 2020).

The COVID-19 has shattered the daily routine, business, schools, lifestyle and the economy of the globe (Gautam and Sharma, 2020). The COVID-19 crisis presents a new type and quality of challenge for companies (Kraus et al., 2020; Kabadayi et al., 2020). At the time of the COVID-19 epidemic, market and business conditions changed overnight for almost all companies (European Commission, 2020). Physical business declined significantly, and companies have become more active online, taking advantage of modern technologies that have not been used before to this extent (Shareena and Mahammad, 2020). As part of the physical distancing measures taken in most EU Member States, employees are obliged to work from home. Most of these employees face first-time as "teleworkers," and their working environment is likely to be deficient in many aspects compared to their workplace in companies' facilities (International Labour Organization, 2020a, b). The extent to which the home environment can be adapted varies according to the situation of the employee and the time and resources available for adaptations (Tam, 2020). The COVID-19 crisis may lead to mental illness for many employees (International Labour Organization, 2020a, b). Many are teleworking full-time for the first time, isolated from coworkers, friends and family. Our daily living routines are disrupted causing added anxiety, stress and strain physically, mentally and financially (International Labour Organization, 2020a, b). Therefore, more and more employees are dealing with stress, depression and anxiety. The problem is that the COVID-19 crisis increases the risk for depression (Institute for employment studies, 2020). According to Wong et al. (2019), mental health at work is a crucial factor for employee well-being, productivity and work engagement.

As employers wrestle with business continuity planning during COVID-19, research according to Gavidia (2020) confirms that employers need to make mental health support a critical aspect of that plan or risk a dramatic impact on employee health and productivity. The COVID-19 pandemic has an impact on employee relations as there is poor communication or face-to-face interactions are missing, which lead to higher stress or symptoms of health problems among employees (Kaushik and Guleria, 2020). Creating and reinforcing relations among individuals at work is basic for information sharing with the goal that companies can rapidly react to the present unique business condition (Chen and Tjosvold, 2012). In such a scenario of the COVID-19 pandemic, the employers are responsible for maintaining harmony in relations (Kaushik and Guleria, 2020). Happy relations between the employee and the employer are key to increase the productivity and performance of both the employee and the company, especially during the COVID-19 (Abrol and Madan, 2020).

Most of the current COVID-19 research focused on health, but research data on physical, emotional, behavioral symptoms of health problems during the COVID-19 pandemic are lacking. This situation calls for academic research providing firms with valid strategies on how to cope with the challenges of the COVID-19 crisis (Qiu et al., 2020). Therefore, the aim of the paper is to highlight which physical, emotional and behavioral symptoms do employees face during the COVID-19 epidemic. Also, the aim of the paper is to examine if there are statistically significant differences in these symptoms of health problems among employees before the COVID-19 epidemic and during the COVID-19 epidemic and to highlight the measures with which companies reduce these problems. Additionally, the aim of the paper is to examine if there are statistically significant differences in different symptoms of health problems of employees who worked from home and those who work at the workplace during the COVID-19 epidemic. 
In Section 2, we present the literature review and hypotheses. It is followed by a description of the methodology (Section 3). The obtained results are introduced in Section 5, followed by the discussion of the results, limitations explanation and further research possibilities (Section 6). The article concludes with an introduction of highlights in the conclusion (Section 7).

Literature review

Importance of better employee relations and human resource management during the COVID-19

The well-being and health of employees should become the topmost priority to overcome this COVID-19 pandemic situation. The unprecedented crisis of COVID-19 has posed an enormous challenge ever for companies to find strategies to deal with their survival (Haque, 2021). The unprecedented crisis of COVID-19 has posed an enormous challenge ever for companies to find strategies to deal with their survival. In the pursuit of improving employee well-being and organizational sustainability, companies need to embrace new strategies and demand more responsibility in their leadership approach to overcome the pandemic situation of COVID-19 (Hamouche, 2020; Leite et al., 2020).

Leadership has been significantly linked to strategic climate to influence both employee well-being and organizational sustainability (Shinbrot et al., 2019). According to Rahimnia and Sharifirad (2015), leadership approaches in companies have substantial effects on employee relations, employee well-being and employee health, including stress and satisfaction (Rahimnia and Sharifirad, 2015). The social support that embodies organizational, supervisor and coworker support fosters psychological safety (Singh et al., 2017). Abrupt crisis and workplace changes have an impact on employee emotional responses. Social support exhibited through mutual trust, open communication and empowerment engenders a sense of stability and safe feeling. Conversely, the lack of support and autonomy leads to low psychological safety and negative emotion. Past studies on psychological safety were associated with learning behavior (e.g. Carmeli and Hoffer, 2009), satisfaction, leader relationship, task performance and citizenship behavior (Frazier et al., 2017) in the physical workplace environment. It was not clear if different groups within the workplace experience similar emotions, psychological safety and organizational support during disruptive events.

Employees are the key assets and driving force in determining the success of a company in a challenging environment, and their commitment is very crucial to any company. Work design measures the physical work environment of where the work is done and ergonomically friendly to the employees in which they feel safe and able to carry out their task effectively in a conducive environment (Agus and Selvaraj, 2020). Mousa et al. (2020) summarize that workplace happiness constantly derives from the direct employee experience of dealing with his or her employer. Accordingly, this attitudinal construct shapes employee behavior and positive feelings toward the work atmosphere, colleagues and the employer. Erdogan et al. (2012) affirm that workplace happiness can be seen as a result of employee satisfaction with their leadership, work atmosphere, good employee relations, job description, job specification, career development and more. Therefore, according to Lee (2021), during the COVID-19 pandemic, there is more need for suitable human resource management in companies and good employee relations because many employees face health problems, like anxiety, tension and depression. According to Mxenge et al. (2014), employees can develop stress if they perceive they are not being furnished with the adequate information and support they require to effectively discharge their job roles or when they feel being bullied in the workplace (Richardson, 2017). Additionally, a poor level of engagement between managers and employees (particularly during the change process) may hinder employees' 
ER

44,7

understanding of their job roles and responsibilities, which can also create and exacerbate their stress level (Kihara and Mugambi, 2018). Srivastava and Agarwal (2020) explain that behavior of the employer affects well-being of employees and also effective in lowering turnover. Thus, a supportive work climate develops work satisfaction among employees resulting in increased organizational performance and employee commitment (Kundu and Lata, 2017).

Employers present the organization and support their subordinates in achieving the organizational goals, and also they take care of good employee relations (Dawley et al., 2010). Poor support from the employer is highly detrimental and might result in absenteeism, dissatisfaction and different symptoms of health problems (Srivastava and Agarwal, 2020). Joo and Lee (2017) emphasize that individuals can be seen as doing well if they have wealth, health, stable employment and emotional stability (Joo and Lee, 2017). The relationship between employers and employees has been in the spotlight these past months. Whether on a collective or individual level, there has naturally been pressure put on these relationships as the business environment and our ways of working have rapidly adapted in response to COVID-19 (Eaton and Heckscher, 2021). Fostering positive employee relations during the COVID-19 leads to beneficial business outcomes and contributes to employees' well-being (Lee, 2021).

Companies that continue to manage employee relations well, despite external pressures, will be best placed to weather the storm of COVID-19 and take advantage of the inevitable opportunities that will arise when the world returns to some form of "business as usual" (Agus and Selvaraj, 2020). According to Zhang et al. (2020) improving employees' well-being is an important human resource management issue and is an essential part of employees' overall life satisfaction. Khoreva and Wechtler (2018) explain that employees who have high levels of well-being tend to be more creative and highly engaged and achieve greater performance at work than those who have low-level well-being. According to Tam (2020), this is very important for a time during the COVID-19 because employees suffer from work overload and psychological anxiety, which is detrimental to organizational performance. During the COVID-19 pandemic, employees face different symptoms of health problems; therefore, we present physical, emotional and behavioral symptoms of health problems in the next subsection.

\section{The negative consequences of COVID-19 for companies}

The COVID-19 pandemic, which started in China and spread to Italy and other EU countries (including Slovenia) in March, in combination with strict containment measures, represents a significant negative shock for economic activity in the euro area (Institute of Macroeconomic Analysis and Development, 2020). The decline in GDP in 2020 will arise from a fall in valueadded in several activities, given the significant contraction in activity for protection measures. This year, in Slovenia value-added, is expected to decline the most in transportation, hotels and restaurants, and personal services. A sharp fall is also expected for the manufacturing sector (Institute of Macroeconomic Analysis and Development, 2020). Owing to the negative impacts from the international environment and foreign and domestic containment measures, coupled with high uncertainty, we can expect a significant decline in exports, imports and investment this year (Institute of Macroeconomic Analysis and Development, 2020). If the strict containment measures, which are significantly hampering business operations in service activities and industry, are extended or tightened, the negative impacts will be more profound and far-reaching. In this case, companies would no longer be able to carry out their activities, and the number of bankruptcies would increase. This would also have greater consequences for the labor market (Institute of Macroeconomic Analysis and Development, 2020). The COVID-19 pandemic has, with alarming speed, delivered a global economic shock of enormous magnitude, leading to steep recessions in many countries. 
The baseline forecast envisions a 5.2\% contraction in global GDP in 2020 - the deepest global recession in eight decades, despite unprecedented policy support (Global Economic Prospects, 2020).

Coronavirus has negatively impacted businesses all over the world. An Executive Trend Survey (Management Events, 2020) of 500 companies found out that 93\% of respondents noting that situation of COVID-19 negatively impact their business. According to the data of Eurostat (2020a), industrial production in the EU dropped by $10.9 \%$ in March 2020 and by $17.3 \%$ in April 2020 compared with previous months. The strongest declines of -33.5 and $-68.5 \%$ were recorded for the manufacturing of motor vehicles (Eurostat, 2020a). Retail trade in the EU dropped by $10.1 \%$ in March 2020 and by $11.1 \%$ in April 2020 compared with previous months. The strongest declines of $-54.1 \%$ and $-21.2 \%$ were recorded for textiles, clothing and leather products (Eurostat, 2020b). Also, in the EU-27, construction production dropped by 11.7\% in April 2020 compared with March 2020 (Eurostat, 2020c). Between February and March 2020, the production of services in the EU dropped by $11.3 \%$. The strongest decline of 48.5\% was recorded for hotels and restaurants (Eurostat, 2020d).

If the strict containment measures, which are significantly hampering business operations in service activities and industry, are extended or tightened, the negative impacts will be more profound and far-reaching. In this case, companies would no longer be able to carry out their activities and the number of bankruptcies would increase. This would also have greater consequences for the labor market (Institute of Macroeconomic Analysis and Development, 2020).

\section{The negative consequences of COVID-19 for employees}

During the COVID-19 pandemic, many employees may be experiencing full-time working from home for the first time, while they are also isolated from coworkers, friends and sometimes even from family. Their daily living routines have been disrupted, which may cause added stress, tension and physical and mental strain. The impact of these stressors is even stronger in the current economic situation. When companies are adversely affected, there can be increased redundancy, lay-offs and terminations, causing workers to feel further anxiety, uncertainty and insecurity, which may result in feelings of depression. The situation is aggravated during mandatory and prolonged working from home when lockdowns prevent people from going out, and social life is limited. Studies have indicated that being unable to interact with friends and isolation from colleagues are key disadvantages in working from home (International Labour Organization, 2020a, b).

Institute for Employment Studies (2020) conducted the COVID-19 homeworker well-being study, looking at how working from home for an extended period is affecting the UK workforce. A snap survey of 500 home employees by the Institute for Employment Studies found that $20 \%$ of respondents admitted to increasing their alcohol consumption, a third said they were eating less healthily and $60 \%$ were doing less exercise. While $64 \%$ reported problems sleeping due to anxiety and $48 \%$ were working irregular work patterns and long days. A third felt lonely. Also, there has been a significant increase in musculoskeletal complaints. More than half of the survey respondents reported new aches and pains, especially in the neck (58\%), shoulder (56\%) and back (55\%), compared to their normal physical condition. Poor sleep and increased risk of exhaustion are also cause of concern. Half of all respondents $(50 \%)$ reported not being happy with their current work-life balance; a third $(33 \%)$ frequently felt isolated, over a fifth $(21 \%)$ were worried about job security, while just under half $(41 \%)$ harbored health concerns for family members (Institute for employment studies, 2020).

A recent study surveyed 1,210 Chinese respondents during the COVID-19 outbreak and found that more than $50 \%$ of respondents reported moderate or severe psychological impact (Wang et al., 2020). COVID-19 was recently found to be associated with neurological 
ER

44,7

damages (Wu et al., 2020). It is important to know that psychiatric symptoms and neurological changes can impair cognitive functioning and work performance (Husain et al., 2020).

The well-being and health of employees should become the topmost priority to overcome this COVID-19 pandemic situation. The unprecedented crisis of COVID-19 has posed an enormous challenge ever for companies to find strategies to deal with their survival (Haque, 2021). In the pursuit of improving employee well-being and organizational sustainability, companies need to embrace new strategies and demand more responsibility in their leadership approach to overcome the pandemic situation of COVID-19 (Hamouche, 2020; Leite et al., 2020).

Leadership has been significantly linked to strategic climate to influence both employee well-being and organizational sustainability (Shinbrot et al., 2019). According to Rahimnia and Sharifirad (2015), leadership approaches in companies have substantial effects on employee relations, employee well-being and employee health, including stress and satisfaction (Rahimnia and Sharifirad, 2015). The social support that embodies organizational, supervisor and coworker support fosters psychological safety (Singh et al., 2017). Abrupt crisis and workplace changes have an impact on employee emotional responses. Social support exhibited through mutual trust, open communication and empowerment engenders a sense of stability and safe feeling. Conversely, the lack of support and autonomy leads to low psychological safety and negative emotion. Past studies on psychological safety were associated with learning behavior (e.g. Carmeli and Hoffer, 2009), satisfaction, leader relationship, task performance and citizenship behavior (Frazier et al., 2017) in the physical workplace environment. It was not clear if different groups within the workplace experience similar emotions, psychological safety and organizational support during disruptive events.

Employees are the key assets and driving force in determining the success of a company in a challenging environment, and their commitment is very crucial to any company. Work design measures the physical work environment of where the work is done and ergonomically friendly to the employees in which they feel safe and able to carry out their task effectively in a conducive environment (Agus and Selvaraj, 2020). Mousa et al. (2020) summarize that workplace happiness is constantly derived from the direct employee experience of dealing with his or her employer. Accordingly, this attitudinal construct shapes employee behavior and positive feelings toward the work atmosphere, colleagues and the employer. Erdogan et al. (2012) affirm that workplace happiness can be seen as a result of employee satisfaction with their leadership, work atmosphere, good employee relations, job description, job specification, career development and more. Therefore, according to Lee (2021), during the COVID-19, there is more need for suitable human resource management in companies and good employee relations because many employees during the COVID-19 face health problems like anxiety, tension and depression. According to Mxenge et al. (2014), employees can develop stress if they perceive they are not being furnished with the adequate information and support they require to effectively discharge their job roles or when they feel being bullied in the workplace (Richardson, 2017). Additionally, a poor level of engagement between managers and employees (particularly during the change process) may hinder employees' understanding of their job roles and responsibilities, which can also create and exacerbate their stress level (Kihara and Mugambi, 2018). Srivastava and Agarwal (2020) explain that behavior of the employer affects the well-being of employees and also effective in lowering turnover. Thus, a supportive work climate develops work satisfaction among employees resulting in increased organizational performance and employee commitment (Kundu and Lata, 2017). 
Employers present the organization and support their subordinates in achieving the organizational goals, and also they take care of good employee relations (Dawley et al., 2010). Poor support from the employer is highly detrimental and might result in absenteeism, dissatisfaction and different symptoms of health problems (Srivastava and Agarwal, 2020). Joo and Lee (2017) emphasize that individuals can be seen as doing well if they have wealth, health, stable employment and emotional stability (Joo and Lee, 2017). The relationship between employers and employees has been in the spotlight these past months. Whether on a collective or individual level, there has naturally been pressure put on these relationships as the business environment and our ways of working have rapidly adapted in response to COVID-19 (Eaton and Heckscher, 2021). Fostering positive employee relations during the COVID-19 leads to beneficial business outcomes and contributes to employees' well-being (Lee, 2021).

Companies that continue to manage employee relations well, despite external pressures, will be best placed to weather the storm of COVID-19 and take advantage of the inevitable opportunities that will arise when the world returns to some form of "business as usual" (Agus and Selvaraj, 2020). According to Zhang et al. (2020) improving employee well-being is an important human resource management issue and is an essential part of employees' overall life satisfaction. Khoreva and Wechtler (2018) explain that employees who have high levels of well-being tend to be more creative and highly engaged and achieve greater performance at work than those who have low-level well-being. According to Tam (2020), this COVID-19 period is very important because employees suffer from work overload and psychological anxiety, which is detrimental to organizational performance. During the COVID-19, employees face different symptoms of health problems; therefore, we present physical, emotional and behavioral symptoms of health problems in the next subsection.

\section{Physical, emotional and behavioral symptoms of health problems}

Mental health refers to cognitive, behavioral and emotional well-being. It is all about how people think, feel and behave. Signs and different symptoms of mental illness can vary, depending on the disorder, circumstances and other factors. Mental illness symptoms can affect emotions, thoughts and behaviors. Sometimes symptoms of a mental health disorder appear as physical problems, such as stomach pain, back pain, headaches or other unexplained aches and pains (see, e.g. Mosadeghrad, 2014; George and Zakkariya, 2015; Rožman et al., 2019; Iavicoli et al., 2020). Different symptoms of health problems are the result of a complex interplay between biological, psychological, social and environmental factors. There is increasing evidence that both the content and context of work can play a role in the development of health problems in the workplace. Key factors include workload (both excessive and insufficient work), lack of participation and control in the workplace, monotonous or unpleasant tasks, role ambiguity or conflict, lack of recognition at work, inequity, poor interpersonal relationships, poor working conditions, poor leadership and communication, conflicting home and work demands (World Health Organization, 2005). According to Mosadeghrad (2014), mental health involves a wide range of emotions, thoughts and behaviors. With good mental health, employees feel well in the workplace, enjoy relations with coworkers and work according to their abilities. Seidler et al. (2014) emphasizes that working conditions have a well-known impact, either positive or negative, on employees' health. Thus, adverse working conditions may lead to different symptoms of health problems (Maslach and Leiter, 2016). This process may lead to undesirable consequences for employees, their families, the work environment and the companies (Maslach et al., 2001). Mosadeghrad (2014) and Ilmarinen (2006) split health problems into physical, emotional and behavioral symptoms. In addition, there are differences in physical, emotional and behavioral symptoms of health problems, which are presented in Figure 1 (Mosadeghrad, 2014; Ilmarinen, 2006): 


\section{ER \\ 44,7}

\section{6}

Figure 1.

Physical, emotional and behavioral symptoms of health problems
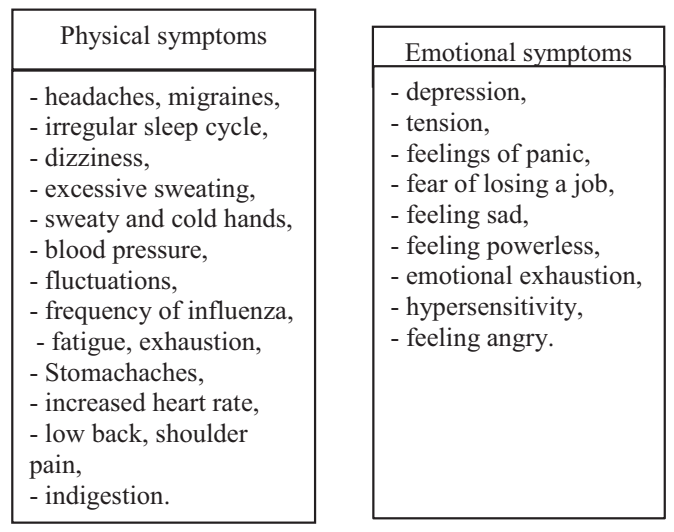

As countries introduce measures to restrict movement as part of efforts to reduce the number of people infected with COVID-19, more and more people are making huge changes to our daily routines. The COVID-19 pandemic means that many people are staying at home and doing less in terms of social interactions and exercise. As already mentioned, this can have a negative effect on their physical and mental health (WHO, 2020b). Stein (2020) emphasizes that the COVID-19 pandemic increases physical, emotional and behavioral symptoms of employees, and this poses a major problem for the health and well-being of employees. During the COVID-19 epidemic, employees face anxiety, depression, insomnia, traumatic distress, hopelessness, nervousness, impaired attention or concentration (Stein, 2020).

Employees indicated that the COVID-19 pandemic was the most stressful time of their entire professional career, which has aligned with stark increases in new prescriptions of antidepressant, antianxiety and antiinsomnia medications (Gavidia, 2020). Also, findings according to Gavidia (2020) indicate not only the stress-induced impact of the COVID-19 pandemic on employees but its major implications for employers as well. In total, $88 \%$ of employees reported experiencing moderate to extreme stress over the past 4-6 weeks. Among those reporting stress, $62 \%$ noted losing at least $1 \mathrm{~h}$ a day in productivity and $32 \%$ lost at least $2 \mathrm{~h}$ a day due to COVID-19-related stress (Gavidia, 2020). Researchers also examined the use of medications to treat three of the most common mental health conditions during the COVID-19 epidemic: depression, anxiety and insomnia, and this provided insights into the impact of the COVID-19 pandemic on America's mental health (Express Scripts, 2020). In the survey, titled “America's State of Mind Report," researchers highlighted that from February to March, prescriptions filled per week for antidepressant, antianxiety and antiinsomnia medications increased by $21 \%$. The rise in new cases may indicate a troubling association with COVID-19-related stress, as 78\% of all three prescriptions filled during the peak week ending March 15 were for new prescriptions (Express Scripts, 2020). Magnavita et al. (2020) in their research on 595 employees found a significant increase in emotional and behavioral symptoms of health problems among employees during the COVID-19 epidemic Based on the results, they found that there was a significant increase in anxiety, depression and insomnia. Also, Magnavita et al. (2020) in their research found a significant increase in physical symptoms among employees during the COVID-19 epidemic, which is reflected in the low sleep quality and stomachaches. Meyer et al. (2021) found out that during the COVID19 epidemic, employees face increasing exhaustion and headaches.

The current study examines if there are differences in physical, behavioral and emotional symptoms of health problems between employees before the COVID-19 epidemic and 
employees during the COVID-19 epidemic. Based on the literature review, we formulated the following research hypotheses:

H1. The physical symptoms of health problems among employees during the COVID-19 epidemic are more strongly expressed as before the COVID-19 epidemic.

H2. The emotional symptoms of health problems among employees during the COVID-19 epidemic are more strongly expressed as before the COVID-19 epidemic.

H3. The behavioral symptoms of health problems among employees during the COVID-19 epidemic are more strongly expressed as before the COVID-19 epidemic.

COVID-19 epidemic has enforced the concept of "work from home" into an officially mandated, strictly enforced rule (Shareena and Mahammad, 2020). At the beginning of the COVID-19 epidemic, the "work from home" concept is emerging from all sectors in Slovenia (Institute of Macroeconomic Analysis and Development, 2020). The "work from home" concept is new to the majority of the employees, as the COVID-19 has forced almost all the employees of all the sectors to work from home for the first time (Shareena and Mahammad, 2020; Tam, 2020). According to an online survey by the Mental Health Association of Hong Kong (Tam, 2020), in Hong Kong, 87\% of employees report suffering from work-induced stress during the COVID-19 pandemic. The survey of 801 people found that about half of all employees show symptoms of an anxiety disorder (Tam, 2020). Research commissioned by LinkedIn (Hayes and Curran, 2020) has given insight into the current working conditions of employees working remotely in Ireland due to COVID-19. The research found that $56 \%$ of respondents reported feeling more anxious or stressed than they did before the lockdown was introduced while respondents also reported working an extra $38 \mathrm{~h}$ per month on average, essentially an additional working week. The current situation is particularly affecting younger workers with $70 \%$ of respondents under 24 and $63 \%$ of respondents between 24 and 34 saying they feel anxious or stressed as a result of working from home (Hayes and Curran, 2020). Oakman et al. (2020) analyzed emotional symptoms of health problems of employees who work at home during the COVID-19. Oakman et al. (2020) in their research found out that employees report higher stress. Hayes et al. (2021) found out that employees who work at home during the COVID-19 face depression and tension. Also, results from the analyses suggest that perceived stress did increase during the COVID-19 restrictions, especially for people that working from home. The results suggest that working from home may create more stress and result in more burnout (Hayes et al., 2021). Giorgi et al. (2020) found out that behavioral symptoms of health problems among employees who worked from home during the COVID-19 reflect insomnia, the decline in working capacity and lack of will to work. According to Giorgi et al. (2020), International Labour Organization (2020a, b) physical symptoms of health problems among employees who worked from home during the COVID-19 epidemic reflect in the irregular sleep cycle, sleep problems, headaches and migraines. Therefore, we wanted to find out if there are statistically significant differences in different symptoms of health problems of employees who worked from home and the workplace during the COVID-19 epidemic.

H4. There are significant differences regarding physical symptoms of health problems among employees who worked from home and those who worked at the workplace during the COVID-19 epidemic.

H5. There are significant differences regarding emotional symptoms of health problems among employees who worked from home and those who worked at the workplace during the COVID-19 epidemic. 
ER

44,7
H6. There are significant differences regarding behavioral symptoms of health problems among employees who worked from home and those who worked at the workplace during the COVID-19 epidemic.

\section{Methodology}

Our empirical research includes two independent samples of employees for two time periods: before the COVID-19 epidemic (930 employees) and during the COVID-19 epidemic (930 employees).

The main survey, conducted from June to August 2020, involved randomly selected 186 large and medium-sized companies in Slovenia, and from each company, five employees participated in our research. Thus, 930 employees responded to the questionnaire. The employer randomly selected five employees who responded to the questionnaire.

The first data collection was carried out from February 2017 to May 2017 as part of a broader research, which among other things, also studied stress in the workplace, and in this part, we used the same measuring instrument.

In the survey during the COVID-19 epidemic, $10.1 \%$ of employees aged from 26 to 31 years, $14.2 \%$ employees aged from 32 to 37 years, $15.9 \%$ employees aged from 38 to 43 years, $18.2 \%$ employees aged from 44 to $49,19.9 \%$ employees aged from 50 to 55 years and $16.5 \%$ employees aged from 56 to 61 years were involved. The lowest percentage is presented by employees aged over $62(5.2 \%$ ) years. According to the length of service, $15.5 \%$ of employees have a length of service from 1 to 10 years, $14.9 \%$ of employees have a length of service from 11 to 20 years, $26.0 \%$ of employees have a length of service from 21 to 30 years, $32.7 \%$ employees have a length of service from 31 to 40 years and $10.9 \%$ employees have a length of service more than 41 years. According to the level of achieved education, $12.2 \%$ finished vocational or secondary school, $36.1 \%$ finished high school, $38.4 \%$ finished university education and $13.3 \%$ finished master's degree or doctorate. The biggest share of companies in which employees are employed present medium-sized companies (54.8\%). Large companies comprised $(45.2 \%)$. The companies in which employees are employed were from manufacturing (26.4\%); trade, maintenance and repair of motor vehicles $(18.8 \%)$; financial and insurance activities $(10.2 \%)$; information and communication activities $(8.6 \%)$; catering (8.1\%); construction (7.5\%); professional, scientific and technical activities $(6.5 \%)$; transport and storage (4.8\%); real estate business (3.2\%); agriculture and hunting, forestry, fishing $(3.2 \%)$, mining $(1.6 \%)$ and other diversified business activities $(1.1 \%)$.

The survey before the COVID-19 epidemic involved 6.9\% employees aged from 20 to 25 years, $9.2 \%$ employees aged from 26 to 31 years, $12.0 \%$ employees aged from 32 to 37 years, $13.3 \%$ employees aged from 38 to 43 years, $19.1 \%$ employees aged from 44 to $49,17.2 \%$ employees aged from 50 to 55 years, $12.7 \%$ employees aged from 56 to 61 years and $9.6 \%$ employees aged over 62 years. According to a length of service, $16.0 \%$ of employees have a length of service from 1 to 10 years, $20.3 \%$ of employees have a length of service from 11 to 20 years, $24.3 \%$ of employees have a length of service from 21 to 30 years, $22.5 \%$ employees have a length of service from 31 to 40 years and $16.9 \%$ employees have a length of service more than 41 years. According to the level of achieved education, $11.8 \%$ finished vocational or secondary school, $35.2 \%$ finished high school, $38.1 \%$ finished university education and $14.9 \%$ finished master's degree or doctorate. The biggest share of companies in which employees are employed present large companies (54.4\%). Medium-sized companies comprised $(45.6 \%)$. The companies in which employees are employed were from manufacturing (27.8\%); trade, maintenance and repair of motor vehicles $(20.6 \%)$; financial and insurance activities (12.4\%); professional, scientific and technical activities (9.8\%); information and communication activities $(8.8 \%)$; agriculture and hunting, forestry, fishing 
(5.6\%); construction (4.1\%); real estate business $(3.2 \%)$; catering $(3.1 \%)$; mining $(2.6 \%)$; transport and storage $(1.2 \%)$ and other diversified business activities $(0.6 \%)$.

\section{Research instrument}

Statements, describing different symptoms of health problems (behavioral symptoms, emotional symptoms and physical symptoms), included in the questionnaire, were designed and tested in empirical research by Mosadeghrad (2014). The respondents indicated their agreement to the listed statements, at a five-point Likert-type scale from 1 - completely disagree to 5 - completely agree.

\section{Statistical analysis}

In the first step, we used descriptive statistics to find the respondents' mean agreements for each statement and standard deviation, which measure the dispersion of a dataset relative to its mean. The standard deviation is also used as a measure of the representativeness of the arithmetic mean, which means that the smaller the standard deviation (compared to the arithmetic mean), the smaller are the differences between the actual values of the variable and its arithmetic mean and vice versa. In determining the average value of agreement/ disagreement, we used the following scale: an average value above 4.50 to 5.00 means that respondents completely agree, an average value above 3.50 to 4.50 means that respondents agree, an average value above 2.50 to 3.50 means that respondents neither agree nor disagree, an average value above 1.50 to 2.50 means that respondents do not agree and an average value of 1.00-1.50 means that respondents completely disagree.

In the next step, we used factor analysis, with the purpose to reduce a large number of measured variables into fewer factors explaining the high proportion of variance of measured variables (Tabachnick and Fidell, 2013). To establish if the use of factor analysis is reasonable, Kaiser (1974) suggests that the value of Kaiser-Meyer-Olkin (KMO) statistics is smaller or equal to 0.5 (KMO $\geq 0.5)$. The reasonableness of the use of factor analysis was additionally tested by Bartlett's test of sphericity $(p<0.05)$. Based on the results of factor analysis, we eliminated those variables whose communalities were lower than 0.40 (Costello and Osborne, 2005). Hair et al. (2010) suggest the minimum level for factor loadings 0.30; factor loadings that are bigger than 0.40 are marked as important, and factor loadings that are bigger than 0.50 are marked as statistically significant. The Varimax factor rotation was used in the case of more than one extracted factor. We saved the derived factor points and with that created new variables (factors). Based on the gained new variables (factors), we analyzed the statistically significant differences of symptoms of health problems among employees.

To test the differences among the groups as defined with the hypotheses set, first, the Kolmogorov-Smirnov and Shapiro-Wilk tests were used to verify the normality of the data distribution (Tabachnick and Fidell, 2013). We found that the data of factors are normally distributed; therefore, we have tested the hypotheses - the differences among employees before the COVID-19 epidemic and during the COVID-19 epidemic - with the parametric $t$-test for two independent samples. To analyze the differences between individual statements, we used the nonparametric Mann-Whitney $U$ test because the data are not normally distributed.

\section{Results}

In the beginning, the results of factor analysis are shown. In the context of factor analysis, we got the factors (i.e. physical, behavioral and emotional symptoms of health problems) that were used for analysis statistically significant differences of symptoms of health problems among employees before the COVID-19 epidemic and during the COVID-19 epidemic with the $t$-test for 
ER 44,7

30

two independent samples. In the second part, with descriptive statistics and the nonparametric Mann-Whitney $U$ test, we analyzed the differences between individual statements within physical, behavioral and emotional symptoms of health problems among employees.

\section{Physical symptoms of health problems among employees}

Table 1 presents the results of factor analysis for the physical symptoms of health problems among employees. The value of KMO measure of sampling adequacy $(\mathrm{KMO}=0.921)$ and the results of Bartlett's test of sphericity $(p<0.01)$ suggested the use of factor analysis.

The values of the communalities for the physical symptoms of health problems among employees are higher than 0.40 (Table 1). In Table 1 , it is presented that from 12 variables two factors explain the $68.7 \%$ variability, namely first factor $56.9 \%$ and second factor $11.8 \%$. We named both factors for physical symptoms of health problems among employees regarding the variables that were included in each factor and present it, namely

(1) Factor 1: Physical symptoms of health problems among employees 1

(2) Factor 2: Physical symptoms of health problems among employees 2

\section{Emotional symptoms of health problems among employees}

Table 2 presents the results of factor analysis for the emotional symptoms of health problems among employees. The value of measure of sampling adequacy $(\mathrm{KMO}=0.871)$ and the results of Bartlett's test of sphericity $(p<0.01)$ suggested the use of factor analysis.

The values of the communalities for the emotional symptoms of health problems among employees are higher than 0.40 (Table 2). In Table 2, it is visible that from 11 variables, two factors are formed which together explain the $66.6 \%$ variability, namely first factor $53.9 \%$ and second factor $12.7 \%$. We named both factors for physical symptoms of health problems among employees regarding the variables that were included in each factor and present it, namely

(1) Factor 1: Emotional symptoms of health problems among employees 1

(2) Factor 2: Emotional symptoms of health problems among employees 2

\begin{tabular}{|c|c|c|c|c|}
\hline \multirow{2}{*}{\multicolumn{2}{|c|}{ Statement }} & \multirow[b]{2}{*}{ Communalities } & \multicolumn{2}{|c|}{ Factor loadings } \\
\hline & & & & 2 \\
\hline \multicolumn{2}{|l|}{ I have headaches, migraines } & 0.478 & 0.295 & 0.625 \\
\hline \multicolumn{2}{|l|}{ My sleep cycle is messy } & 0.702 & 0.158 & 0.823 \\
\hline \multicolumn{2}{|l|}{ I have vertigo } & 0.757 & 0.827 & 0.271 \\
\hline \multicolumn{2}{|l|}{ I'm sweating } & 0.859 & 0.894 & 0.245 \\
\hline \multicolumn{2}{|c|}{ I have sweaty and cold hands } & 0.885 & 0.907 & 0.250 \\
\hline \multicolumn{2}{|l|}{ My blood pressure varies } & 0.842 & 0.873 & 0.283 \\
\hline \multicolumn{2}{|l|}{ I often have the flu or viruses } & 0.630 & 0.651 & 0.453 \\
\hline \multicolumn{2}{|l|}{ I am often tired, exhausted } & 0.625 & 0.208 & 0.763 \\
\hline \multicolumn{2}{|l|}{ I have stomach aches } & 0.584 & 0.343 & 0.683 \\
\hline \multicolumn{2}{|c|}{$\begin{array}{l}\text { I have an increased heart rate } \\
\text { a }\end{array}$} & 0.635 & 0.608 & 0.516 \\
\hline \multicolumn{2}{|c|}{ I have lower back pain, shoulder pain } & 0.659 & 0.245 & 0.774 \\
\hline \multicolumn{2}{|l|}{ I have indigestion } & 0.585 & 0.433 & 0.630 \\
\hline \multicolumn{5}{|l|}{ KMO measure: 0.921} \\
\hline \multirow[t]{2}{*}{ Bartlett's test of sphericity } & Approx. chi-square & 16596.529 & & \\
\hline & $\begin{array}{l}\text { df } \\
\text { Sig }\end{array}$ & 66 & & \\
\hline Cumulative percentage of $\mathrm{e}$ & $\begin{array}{l}\text { Sig } \\
\text { d variance for both } \mathrm{fac}_{\mathrm{c}}\end{array}$ & $\begin{array}{c}0.000 \\
\text { gether: } 68.687 \%\end{array}$ & & \\
\hline
\end{tabular}

Table 1.

The results of factor analysis for the physical symptoms of health problems among employees 


\begin{tabular}{|c|c|c|c|c|c|}
\hline \multirow{2}{*}{\multicolumn{2}{|c|}{ Statement }} & & \multicolumn{2}{|c|}{ Factor loadings } & \\
\hline & & Communalities & 1 & 2 & \\
\hline \multicolumn{2}{|l|}{ I have depressive feelings } & 0.524 & 0.573 & 0.443 & \\
\hline \multicolumn{2}{|l|}{ I am tense } & 0.434 & 0.388 & 0.533 & \\
\hline \multicolumn{2}{|l|}{ I feel panic } & 0.744 & 0.109 & 0.855 & \\
\hline \multicolumn{2}{|c|}{$\begin{array}{l}\text { I am afraid of losing the job or not finishing the work on } \\
\text { schedule }\end{array}$} & 0.547 & 0.704 & 0.225 & 31 \\
\hline \multicolumn{2}{|c|}{ I am sad } & 0.807 & 0.148 & 0.886 & \\
\hline \multicolumn{2}{|l|}{ I have a feeling of helplessness } & 0.644 & 0.362 & 0.716 & \\
\hline \multicolumn{2}{|c|}{$\begin{array}{l}\text { To me, everything seems meaningless } \\
\text { I am emotionally exhausted }\end{array}$} & 0.755 & 0.861 & 0.116 & \\
\hline \multicolumn{2}{|c|}{ I am emotionally exhausted } & 0.797 & 0.863 & 0.228 & \\
\hline \multicolumn{2}{|l|}{ I am exceedingly sensitive } & 0.800 & 0.866 & 0.223 & \\
\hline \multirow{2}{*}{\multicolumn{2}{|c|}{$\begin{array}{l}\text { I am quarrelsome } \\
\text { I feel anger }\end{array}$}} & 0.660 & 0.658 & 0.477 & \\
\hline & & 0.618 & 0.572 & 0.539 & Table 2. \\
\hline & & & The results of factor \\
\hline Bartlett's test of sphericity & Approx. chi-square & 15035.370 & & & analysis for the \\
\hline & $\begin{array}{l}\text { df } \\
\text { Sig }\end{array}$ & $\begin{array}{l}55 \\
0.000\end{array}$ & & & $\begin{array}{l}\text { emotional symptoms of } \\
\text { health problems }\end{array}$ \\
\hline Cumulative percentage of ex & ed variance for both fa & ogether: $66.642 \%$ & & & among employees \\
\hline
\end{tabular}

\section{Behavioral symptoms of health problems among employees}

Value of KMO measure of sampling adequacy $(\mathrm{KMO}=0.865)$ and the results of Bartlett's test of sphericity $(\phi<0.01)$ suggested the use of factor analysis. Table 3 presents the results of factor analysis for the behavioral symptoms of health problems among employees.

The values of the communalities for the behavioral symptoms of health problems among employees are higher than 0.40 (Table 3 ). In Table 3 , it is visible that from eight variables, two factors are formed which together explain the $69.3 \%$ variability, namely first factor $55.3 \%$ and second factor $13.9 \%$. We named both factors for physical symptoms of health problems among employees regarding the variables that were included in each factor and present it, namely:

(1) Factor 1: behavioral symptoms of health problems among employees 1

(2) Factor 2: behavioral symptoms of health problems among employees 2

The results of statistically significant differences of symptoms of health problems among employees before the COVID-19 epidemic and during the COVID-19 epidemic

The Kolmogorov-Smirnov and Shapiro-Wilk test show that data of factors are normally distributed $(p>0.05)$; therefore, the significance of differences between two independent samples was tested with the $t$-test for two independent samples. Table 4 shows the results of statistically significant differences in physical, behavioral and emotional symptoms of health problems (factors) among employees before the COVID-19 epidemic and during the COVID-19 epidemic.

Based on the results of the $t$-test for two independent samples $(p<0.05)$, we found that the physical, behavioral and emotional symptoms of health problems among employees during the COVID-19 epidemic are more strongly expressed as before the COVID-19 epidemic (Tables 4-7). The results in Table 4 show that there are statistically significant differences in physical symptoms of health problems among employees 2 (headaches and migraines; messy sleep cycle; frequency of tiredness and exhaustion; stomach aches, indigestion, lower back pain and shoulder pain), but not in physical symptoms of health 


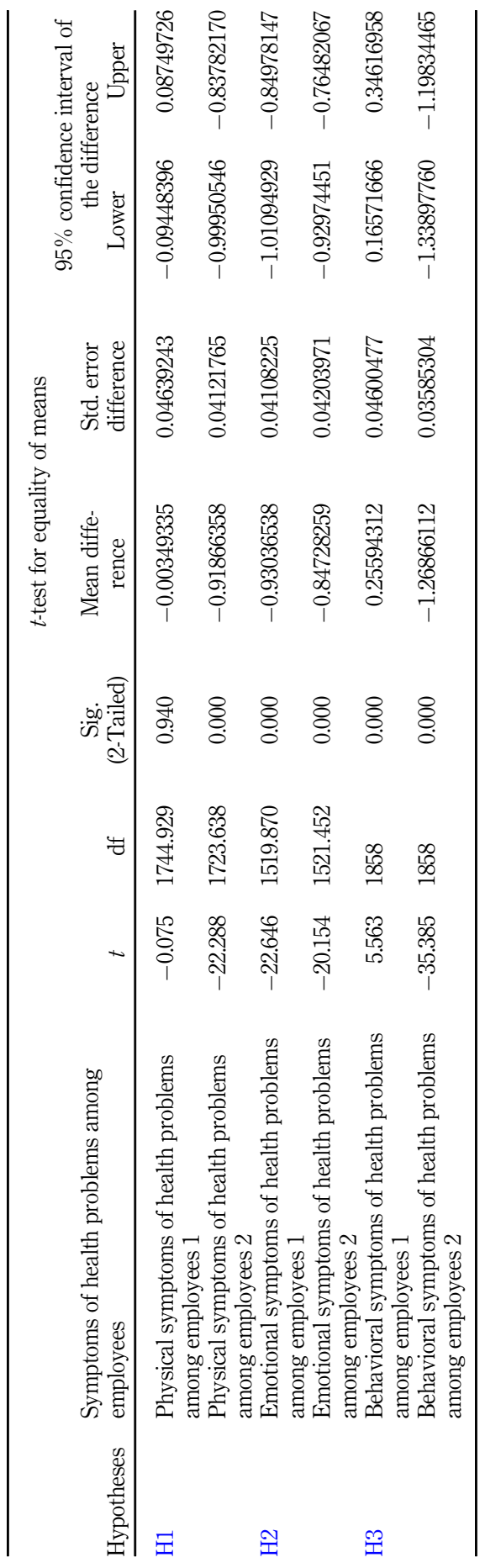

Health problems

33

Table 4. The results of statistically significant differences of symptoms of health problems among employees before the COVID-19 epidemic and during the COVID-19 epidemic 


\section{ER 44,7}

Table 5.

Descriptive statistics and statistically significant differences in physical symptoms of health problems of employees before the COVID-19 epidemic and during the COVID-19 epidemic

\begin{tabular}{|c|c|c|c|c|c|c|}
\hline Statement & $\begin{array}{l}\text { Befor } \\
\text { Mean }\end{array}$ & $\begin{array}{l}\text { e COVID-19 } \\
\text { demic } \\
\text { Standard } \\
\text { deviation }\end{array}$ & $\begin{array}{l}\text { During } \\
\text { Mean }\end{array}$ & $\begin{array}{l}\text { demic } \\
\text { Standard } \\
\text { deviation }\end{array}$ & $\begin{array}{c}\text { Mann- } \\
\text { Whitney } U \text { test }\end{array}$ & $\begin{array}{l}\text { Asymp. Sig. } \\
\text { (2-Tailed) }\end{array}$ \\
\hline $\begin{array}{l}\text { I have headaches, } \\
\text { migraines }\end{array}$ & 3.31 & 1.146 & 4.11 & 1.154 & 260032.000 & 0.000 \\
\hline $\begin{array}{l}\text { My sleep cycle is } \\
\text { messy }\end{array}$ & 3.53 & 1.099 & 4.45 & 0.891 & 219794.500 & 0.000 \\
\hline I have vertigo & 2.46 & 1.066 & 2.95 & 1.365 & 350946.000 & 0.000 \\
\hline I'm sweating & 2.47 & 1.079 & 2.78 & 1.282 & 380319.000 & 0.000 \\
\hline $\begin{array}{l}\text { I have sweaty and } \\
\text { cold hands }\end{array}$ & 2.41 & 1.065 & 2.74 & 1.284 & 375449.000 & 0.000 \\
\hline $\begin{array}{l}\text { My blood pressure } \\
\text { varies }\end{array}$ & 2.63 & 1.102 & 2.90 & 1.260 & 382670.500 & 0.000 \\
\hline $\begin{array}{l}\text { I often have the flu or } \\
\text { viruses }\end{array}$ & 2.83 & 1.105 & 3.19 & 1.261 & 363967.500 & 0.000 \\
\hline $\begin{array}{l}\text { I am often tired, } \\
\text { exhausted }\end{array}$ & 3.43 & 1.066 & 4.30 & 0.959 & 230936.500 & 0.000 \\
\hline I have stomach aches & 2.83 & 1.159 & 3.61 & 1.325 & 287657.500 & 0.000 \\
\hline $\begin{array}{l}\text { I have an increased } \\
\text { heart rate }\end{array}$ & 2.76 & 1.124 & 3.11 & 1.239 & 364151.500 & 0.000 \\
\hline $\begin{array}{l}\text { I have lower back } \\
\text { pain, shoulder pain }\end{array}$ & 3.47 & 1.118 & 4.17 & 1.016 & 272668.000 & 0.000 \\
\hline I have indigestion & 2.77 & 1.155 & 3.56 & 1.351 & 292357.500 & 0.000 \\
\hline
\end{tabular}

\section{Table 6.}

Descriptive statistics and statistically significant differences in emotional symptoms of health problems of employees before the COVID-19 epidemic and during the COVID-19 epidemic

\begin{tabular}{|c|c|c|c|c|c|c|}
\hline Statement & $\begin{array}{l}\text { Before } \\
\text { Mean } \\
\end{array}$ & $\begin{array}{l}\text { e COVID-19 } \\
\text { demic } \\
\text { Standard } \\
\text { deviation }\end{array}$ & $\begin{array}{r}\mathrm{D} \\
\text { COVI } \\
\text { Mean } \\
\end{array}$ & $\begin{array}{l}\text { ing the } \\
19 \text { epidemic } \\
\text { Standard } \\
\text { deviation }\end{array}$ & $\begin{array}{l}\text { Mann- } \\
\text { Whitney } U \\
\text { test } \\
\end{array}$ & $\begin{array}{l}\text { Asymp. Sig. } \\
\text { (2-Tailed) }\end{array}$ \\
\hline I have depressive feelings & 2.35 & 1.027 & 4.32 & 1.240 & 112819.500 & 0.000 \\
\hline I am tense & 3.35 & 1.065 & 3.77 & 1.141 & 337604.500 & 0.000 \\
\hline I feel panic & 2.28 & 0.964 & 3.69 & 1.490 & 209692.000 & 0.000 \\
\hline $\begin{array}{l}\text { I am afraid of losing the job } \\
\text { or not finishing the work on } \\
\text { schedule }\end{array}$ & 2.82 & 1.135 & 4.16 & 1.286 & 191011.500 & 0.000 \\
\hline I am sad & 2.45 & 1.106 & 3.71 & 1.482 & 228106.500 & 0.000 \\
\hline $\begin{array}{l}\text { I have a feeling of } \\
\text { helplessness }\end{array}$ & 2.26 & 0.978 & 3.75 & 1.519 & 201416.500 & 0.000 \\
\hline $\begin{array}{l}\text { To me, everything seems } \\
\text { meaningless }\end{array}$ & 2.18 & 0.943 & 3.69 & 1.529 & 200962.000 & 0.000 \\
\hline I am emotionally exhausted & 2.59 & 1.126 & 3.98 & 1.400 & 197518.500 & 0.000 \\
\hline I am exceedingly sensitive & 2.47 & 1.075 & 3.68 & 1.482 & 231779.500 & 0.000 \\
\hline I am quarrelsome & 2.37 & 1.013 & 3.57 & 1.540 & 243610.000 & 0.000 \\
\hline I feel anger & 2.32 & 0.997 & 3.68 & 1.535 & 219432.500 & 0.000 \\
\hline
\end{tabular}

shoulder pain (mean: 4.17), I have headaches, migraines (mean: 4.11), I have stomach aches (mean: 3.61) and I have indigestion (mean: 3.56). In the other cases, employees on average neither agreed nor disagreed. The highest dispersion of responses (standard deviation) during the COVID-19 epidemic is observed in the statement "I have vertigo." This means that agreement with the statements differs most in this indicator. The lowest dispersion of responses (standard deviation) during the COVID-19 epidemic is observed in the statement 
"My sleep cycle is messy." The results of means for answers about the physical symptoms of health problems of employees before the COVID-19 epidemic indicate that, on average, employees had the highest agreement with messy sleep cycle (mean: 3.53). In the other cases, employees on average neither agreed nor disagreed. The highest dispersion of responses (standard deviation) before the COVID-19 epidemic is observed in the statement "I have stomach aches." The lowest dispersion of responses (standard deviation) before the COVID-19 epidemic is observed in the statement "I have sweaty and cold hands."

The results (Table 6) indicate that, on average, the emotional symptoms of health problems of employees during the COVID-19 epidemic are higher than emotional symptoms of health problems of employees before the COVID-19 epidemic. Table 6 shows that the means for answers about the emotional symptoms of health problems of employees during the COVID-19 epidemic indicate that, on average, employees had the highest agreement with depressive feelings (mean: 4.32), afraid of losing the job or not finishing the work on a schedule (mean: 4.16), tension (mean: 3.77), feeling of helplessness (mean: 3.75), sadness (mean: 3.71), etc. Also, the results show that employees during the COVID-19 epidemic on average agree with all statements relating to emotional symptoms of health problems. On the other hand, results indicate that employees before the COVID-19 epidemic on average disagree with eight statements and neither agreed nor disagreed with three statements. The highest dispersion of responses (standard deviation) during the COVID-19 epidemic is observed in the statement "I am quarrelsome," and the lowest dispersion of responses is observed in the statement "I am tense." The highest dispersion of responses (standard deviation) before the COVID-19 epidemic is observed in the statement "I am afraid of losing the job or not finishing the work on schedule," and the lowest dispersion of responses is observed in the statement "To me, everything seems meaningless."

The results (Table 7) show that, on average, the behavioral symptoms of health problems of employees during the COVID-19 epidemic are higher than behavioral symptoms of health problems of employees before the COVID-19 epidemic, except the desire for solitude and the lack of will to socialize with coworkers are lower. Table 7 shows that the means for answers about the behavioral symptoms of health problems of employees during the COVID-19 epidemic indicate that, on average, employees had the highest agreement with: I have insomnia (mean: 4.54), I avoid activities (mean: 3.92), my working ability has declined (mean: 3.69) and I have nightmares (mean: 3.53). Also, employees on average neither agree nor disagree with the statement "I have difficulties

\begin{tabular}{|c|c|c|c|c|c|c|c|}
\hline Statement & $\begin{array}{l}\text { Before } \\
\text { Mean }\end{array}$ & $\begin{array}{l}\text { e COVID-19 } \\
\text { demic } \\
\text { Standard } \\
\text { deviation }\end{array}$ & $\begin{array}{l}\text { Durin } \\
\text { Mean }\end{array}$ & $\begin{array}{l}\text { e COVID-19 } \\
\text { demic } \\
\text { Standard } \\
\text { deviation }\end{array}$ & $\begin{array}{c}\text { Mann- } \\
\text { Whitney } U \\
\text { test }\end{array}$ & $\begin{array}{c}\text { Asymp. Sig. } \\
\text { (2-Tailed) }\end{array}$ & \\
\hline I avoid activities & 2.60 & 1.041 & 3.92 & 1.320 & 195426.000 & 0.000 & \\
\hline I have nightmares & 2.61 & 1.149 & 3.53 & 1.466 & 277853.000 & 0.000 & \\
\hline I have insomnia & 3.43 & 1.088 & 4.54 & 0.928 & 180752.500 & 0.000 & \\
\hline $\begin{array}{l}\text { I have difficulties with } \\
\text { concentration and } \\
\text { memory }\end{array}$ & 2.40 & 0.991 & 2.54 & 1.119 & 408025.000 & 0.027 & $\begin{array}{r}\text { Table } 7 . \\
\text { Descriptive statistics } \\
\text { and statistically }\end{array}$ \\
\hline I wish for solitude & 2.30 & 1.012 & 2.19 & 1.007 & 405291.000 & 0.012 & in behavioral \\
\hline $\begin{array}{l}\text { My working ability has } \\
\text { declined }\end{array}$ & 2.71 & 1.107 & 3.69 & 1.375 & 258264.000 & 0.000 & $\begin{array}{l}\text { symptoms of health } \\
\text { problems of emplovees }\end{array}$ \\
\hline I lack the will to work & 2.54 & 1.090 & 3.25 & 1.433 & 311309.500 & 0.000 & before the COVID-19 \\
\hline $\begin{array}{l}\text { I lack the will to socialize } \\
\text { with co-workers }\end{array}$ & 2.46 & 1.058 & 2.28 & 0.995 & 397146.500 & 0.001 & $\begin{array}{l}\text { epidemic and during } \\
\text { the COVID-19 epidemic }\end{array}$ \\
\hline
\end{tabular}


ER

44,7

with concentration and memory" and "I lack the will to work." Also, employees on average disagree with statements "I lack the will to socialize with co-workers" and "I wish for solitude." On the other hand, results indicate that employees before the COVID-19 epidemic on average disagree with three statements and neither agreed nor disagreed with five statements. The highest dispersion of responses (standard deviation) during the COVID-19 epidemic is observed in the statement "I have nightmares," and the lowest dispersion of responses is observed in the statement "I have insomnia." The highest dispersion of responses (standard deviation) before the COVID-19 epidemic is observed in the statement "I have nightmares," and the lowest dispersion of responses is observed in the statement "I have difficulties with concentration and memory."

Based on the results of the nonparametric Mann-Whitney $U$ test $(p<0.05)$, we confirmed hypothesis 1 (the physical symptoms of health problems among employees during the COVID-19 epidemic are more strongly expressed as before the COVID-19 epidemic), hypothesis 2 (the emotional symptoms of health problems among employees during the COVID-19 epidemic are more strongly expressed as before the COVID-19 epidemic) and hypothesis 3 (the behavioral symptoms of health problems among employees during the COVID-19 epidemic are more strongly expressed as before the COVID-19 epidemic).

The results of testing the hypotheses $\mathrm{H} 4, \mathrm{H} 5$ and $\mathrm{H} 6$ are presented in Table 8.

Based on the results of the $t$-test for two independent samples $(p<0.05)$, we found that there are statistically significant differences in the physical, emotional and behavioral symptoms of health problems among employees who worked from home and from the workplace during the COVID-19 epidemic. The results in Table 8 show that there are statistically significant differences in physical symptoms of health problems among employees 2 (headaches and migraines; messy sleep cycle; frequency of tiredness and exhaustion; stomach aches, indigestion, lower back pain and shoulder pain), but not in physical symptoms of health problems among employees 1 (vertigo; sweating; sweaty and cold hands; changing blood pressure; frequency of flu or viruses and increased heart rate) among employees who worked from home and from the workplace during the COVID-19 epidemic. In addition, the results show that there are statistically significant differences in emotional symptoms of health problems among employees 2 (tension, a sense of panic, sadness and feeling of helplessness), but not in emotional symptoms of health problems among employees 1 (depressive feelings, afraidness of losing the job or not finishing the work on schedule, everything is seeming meaningless, emotional exhaustion, extreme sensitivity, quarrelsome and feeling of anger) among employees who worked from home and from the workplace during the COVID-19 epidemic. Also, the results show that there are statistically significant differences in behavioral symptoms of health problems among employees 1 (difficulties with concentration and memory, the wish for solitude, declined working ability, lack of the will to work and lack of the will to socialize with coworkers), but not in behavioral symptoms of health problems among employees 2 (avoidance of activities, nightmares, insomnia) among employees who worked from home and from the workplace during the COVID-19 epidemic. The results of the $t$-test also show that there is a difference between the mean values from each data set (mean difference). Based on the results of the $t$-test for two independent samples $(p<0.05)$, we confirmed hypothesis $\mathrm{H} 4$ (there are significant differences regarding physical symptoms of health problems among employees who worked from home and those who worked at the workplace during the COVID-19 epidemic), hypothesis H5 (there are significant differences regarding emotional symptoms of health problems among employees who worked from home and those who worked at the workplace during the COVID-19 epidemic) and hypothesis H6 (there are significant differences regarding behavioral symptoms of health problems among employees who worked from home and those who worked at the workplace during the COVID-19 epidemic). 


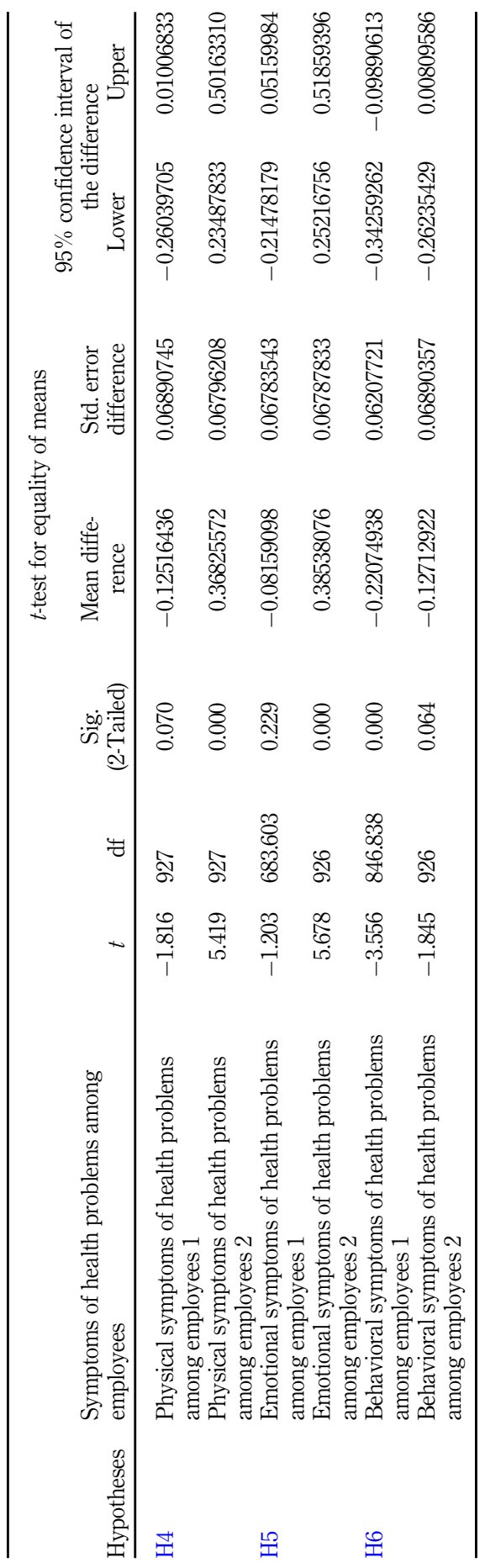

Health problems

Table 8

The results of statistically significant differences in different symptoms of health problems of employees who worked from home and from the workplace during the COVID-19 epidemic 
ER

44,7

\section{Discussion}

The results showed that the physical, behavioral and emotional symptoms of health problems among employees during the COVID-19 epidemic are more strongly expressed as before the COVID-19 epidemic. The results are in line with the findings of WHO (2020b) and the Institute for Employment Studies (2020) in which researchers found out that the physical symptoms manifest in sleeping problems, pains in the neck, shoulder and back. In our research, we found an increase in physical symptoms, such as messy sleep cycle, tiredness and exhaustion, lower back pain and shoulder pain, headaches and migraines, stomach aches and indigestion among the employees during the COVID-19 epidemic. Also, the extent to which the physical symptoms of health problems of employees are expressed during the COVID-19 epidemic is higher than compared to before.

Additionally, the results showed that there are statistically significant differences in the emotional symptoms of health problems among employees before the COVID-19 epidemic and during the COVID-19 epidemic, which is in line with findings of Stein (2020), Institute for employment studies (2020) and International Labour Organization (2020a, b) in which research studies found out that the emotional symptoms indicate in stress, depression and anxiety (Stein, 2020; Institute for employment studies, 2020; International Labour Organization, 2020a, b). Also, employees are worried about job security (Institute for employment studies, 2020). In addition, Stein (2020) adds hopelessness and nervousness. In our research, we found an increase in emotional symptoms, such as depressive feelings, afraid of losing the job or not finishing the work on schedule, tension, feeling of helplessness, sadness, emotional exhaustion, feeling panic, everything seems meaningless, extreme sensitivity, feeling anger and quarrelsome, among employees during the COVID-19 epidemic. Also, the average of the answers about the emotional symptoms of health problems of employees during the COVID-19 epidemic is greatly increased in comparison with emotional symptoms of health problems among employees before the COVID-19 epidemic. The extent to which the emotional symptoms of health problems of employees are expressed during the COVID-19 epidemic is higher than compared to before.

Based on the results, we found out that there are statistically significant differences in the behavioral symptoms of health problems among employees before the COVID-19 epidemic and employees during the COVID-19 epidemic. This is in line with the findings of Gavidia (2020), the Institute for employment studies (2020) and the International Labour Organization $(2020 \mathrm{a}, \mathrm{b})$ in which researchers found out that the COVID-19 epidemic has a negative effect on the employee's health and well-being. They also found out that the COVID-19 epidemic reduces employee productivity and the employee's willingness to work. Also, employees feel isolated and lonely. In addition, Stein (2020) adds insomnia, traumatic distress and impaired attention or concentration. Based on our research we found out that on average, the behavioral symptoms of health problems of employees during the COVID-19 epidemic are higher than behavioral symptoms of health problems of employees before the COVID-19 epidemic, except the desire for solitude and the lack of will to socialize with coworkers are lower. The results of our research show that the behavioral symptoms of health problems of employees during the COVID-19 epidemic show that employees face insomnia, avoid activities declined working ability and nightmares. Employees on average neither agree nor disagree with difficulties with concentration and memory and lack willingness to work. The extent to which the behavioral symptoms of health problems of employees are expressed during the COVID-19 epidemic is higher than compared to before.

The results also indicate that there are statistically significant differences in the physical, emotional and behavioral symptoms of health problems among employees who worked from home and from the workplace during the COVID-19 epidemic. Thus, we found out that there are statistically significant differences in physical symptoms of health problems among 
employees 2 (factor 2): headaches and migraines; messy sleep cycle; frequency of tiredness and exhaustion; stomach aches, indigestion, lower back pain and shoulder pain. In addition, the results show that there are statistically significant differences in emotional symptoms of health problems among employees 2 (factor 2): tension, a sense of panic, sadness and a feeling of helplessness. Also, the results show that there are statistically significant differences in behavioral symptoms of health problems among employees 1 (factor 1): difficulties with concentration and memory, the wish for solitude, declined working ability, lack of the will to work and lack the will to socialize with coworkers. This is consistent with the findings of company Lenovo Group Ltd (Schoot, 2020), Tam (2020) and Hayes and Curran (2020) in which researchers found out that the most common symptoms of employees who worked from home during the COVID-19 epidemic are back pain, poor posture (e.g. hunched shoulders), neck pain, eye irritation, messy sleep cycle, insomnia and headaches. Tam (2020) added loneliness, a sense of loss and anxiety.

Implications for practice are reflected in developing an adequate working environment for employees during the COVID-19 epidemic. Employers or managers can use the findings to create an appropriate work environment with appropriate working conditions with which they can reduce or eliminate physical, emotional, behavioral symptoms of health problems among employees during the COVID-19 epidemic. A good understanding of which physical, emotional and behavioral symptoms of health problems do employees face during the COVID-19 epidemic could improve better health, well-being, productivity and satisfaction among employees during the COVID-19 and also after the COVID-19. According to Lee (2021), Agus and Selvaraj (2020), Srivastava and Agarwal (2020), Zhang et al. (2020), Shareena and Mahammad (2020) and Hayes and Curran (2020), there is more need for suitable human resource management during the COVID-19 epidemic and suitable working environment for employees during the COVID-19 epidemic and also after the COVID-19 epidemic. Moreover, Stein (2020), Gavidia (2020), Magnavita et al. (2020), Oakman et al. (2020) and Meyer et al. (2021) emphasize that managers should analyze which physical, emotional and behavioral symptoms of health problems do employees face during the COVID-19, and based on this, a pleasant working environment for employees could be created. This research provides guidance for managers who wonder what they should do to improve better health and well-being of their employees during the COVID-19. The study findings show that physical, emotional and behavioral symptoms of health problems among employees during the COVID-19 epidemic are more strongly expressed as before the COVID-19 epidemic, and also the study findings show that there are significant differences regarding physical, emotional, and behavioral symptoms of health problems among employees who worked from home and those who worked at the workplace during the COVID-19 epidemic. Managers can use this study results to enhance the management system and to improve better health, well-being and the productivity of employees through improving working conditions during the COVID-19. The findings of this study could be utilized for the managerial practice and improvement of organizations' human resource policy. As there is no effective vaccine and treatment against COVID-19, the preventive measures at the workplace should include personal preventive measures (e.g. hand hygiene, wearing a face mask and other personal precaution) and organizational measures (e.g. good ventilation, social distancing at work and COVID-19 testing for employees). Organizational measures which include improvement of workplace hygiene and concerns from the company on physical health status lead to less psychiatric symptoms of employees. But, on the other hand, companies should look for ways to reduce the physical, emotional and behavioral symptoms of employees during COVID-19. Fulltime remote work has been a drastic change for the vast majority of employees. For many, working remotely has meant isolation from coworkers, friends and even family. Therefore, we recommend that employers should consider the following. Employers should stay 
ER

44,7

connected by utilizing current technology to connect with their employees in real-time over the phone and through video for regularly scheduled check-ins. This can include businessrelated check-ins or something less formal, such as grabbing coffee together over video or holding an informal video with a group of colleagues to catch up. Thus, employers should create an environment of open communication, so employees can speak openly about their concerns. This would make employees feel less isolated, helpless, tensed or sad. Also, employers should train managers or human resources professionals to ensure that they are proactively identifying signs of employee distress, such as erratic work hours, lack of availability or responsiveness, or sudden and unexplained changes in work product. Employers should organize employee assistance programs and any additional mental health services or support that the company may offer. This would not reduce employee productivity or working ability and willingness of employees to work. Also, such measures would help to reduce depressive feelings. Companies should be supportive of employee well-being. Employee well-being, the physical and mental health are crucial to the morale and productivity of the company as a whole. Therefore, employers should give employees a chance to share their concerns by appointing a person in the company to field questions or providing a way for employees to submit questions anonymously. Employers should consider wellness offerings like access to telehealth providers and online stressmanagement workshops. While the first few weeks of a crisis are the most stressful as employees adjust. The well-being of employees must be the company's top priority. Companies also need to implement psychological support systems to provide a safe and healthy working environment to minimize potential anxiety and stress when employees return to work. Also, government and health authorities need to provide accurate health information during the epidemic to reduce the impact of rumors. Higher satisfaction with the health information received is associated with a lower psychological impact of the outbreak and lower levels of stress, anxiety and depression. The content of health information provided during the epidemic needs to be based on evidence to avoid adverse psychological reactions. According to Wang et al. (2020), additional information on medicines or vaccines, routes of transmission and updates on the number of infected cases and location (e.g. real-time, online tracking map) were associated with lower levels of anxiety.

Our sample was limited to employees in Slovenian medium- and large-sized companies. Also, our research was limited to physical, emotional and behavioral symptoms of health problems. Therefore, for further research we propose the examination of differences in others constructs (for example, work motivation, work satisfaction and work engagement) before the COVID-19 epidemic and employees during the COVID-19 epidemic. Possibilities for further research also include studies relating to the examination of physical, emotional and behavioral symptoms of health problems in different countries.

\section{Conclusion}

Our findings shed light on the need for companies to be aware of the extent and factors associated with symptoms, among employees during the COVID-19 pandemic. Our research shows that there are statistically significant differences in the physical, emotional and behavioral symptoms of health problems among employees before the COVID-19 epidemic and employees during the COVID-19 epidemic. Also, our research highlights physical, emotional and behavioral symptoms faced by employees during the COVID-19 epidemic. We also presented the measures with which companies can reduce the problem of these different symptoms of employees during the COVID-19 epidemic. According to Tan et al. (2020), there will be a new model of the economy based on psychoneuroimmunity preventive measures, whereby the focus will be on protecting the immunity and health of employees against COVID-19 and at the same time, not sacrificing productivity. 


\section{References}

Abrol, S. and Madan, V. (2020), "Coronavirus: employer and employee relationship", available at: https://akshmisri.com/insights/articles/coronavirus-employer-andemployeerelationship/.

Agus, A. and Selvaraj, R. (2020), "The mediating role of employee commitment in the relationship between quality of work life and the intention to stay", Employee Relations, Vol. 42 No. 6, pp. 1231-1248.

Baker, S., Bloom, N., Davis, S.J., Kost, K., Sammon, M. and Viratyosin, T. (2020), “The unprecedented stock market reaction to COVID-19", Covid Economics: Vetted and Real-Time Papers, Vol. 1 No. 3, pp. 1-24.

Carmeli, A. and Hoffer, J. (2009), "High-quality relationships, psychological safety, and learning from failures in work organizations", Journal of Organizational Behavior, Vol. 30, pp. 709-729.

Chen, G. and Tjosvold, D. (2012), "Shared rewards and goal interdependence for psychological safety among departments in China", Asia Pacific Journal of Management, Vol. 29, pp. 433-452.

Costello, A.M. and Osborne, J.W. (2005), "Best practices in exploratory factor analysis: four recommendations for getting the most from your analysis", Practical Assessment, Research and Evaluation, Vol. 10 No. 7, pp. 1-9.

Dawley, D., Houghton, D.J. and Bucklew, S.N. (2010), "Perceived organizational support and turnover intention: the mediating effects of personal sacrifice and job fit", The Journal of Social Psychology, Vol. 150 No. 3, pp. 238-257.

del Rio-Chanona, R.M., Mealy, P., Pichler, A., Lafond, F. and Farmer, D. (2020), "Supply and demand shocks in the COVID-19 pandemic: an industry and occupation perspective", available at: https://www.researchgate.net/publication/340662439_Supply_and_demand_shocks_in_the_ COVID-19_pandemic_An_industry_and_occupation_perspective.

Eaton, A. and Heckscher, C. (2021), "COVID's impacts on the field of Labour and employment relations", Journal of Management Studies, Vol. 58 No. 1, pp. 275-279.

Erdogan, B., Bauer, T.N., Truxillo, D.M. and Mansfield, L.R. (2012), "Whistle while you work a review of the life satisfaction literature", Journal of Management, Vol. 38 No. 4, pp. 1038-1083.

European Commission (2020), "Coronavirus response", available at: https://ec.europa.eu/info/livework-travel-eu/health/coronavirus-response_en.

Eurostat (2020a), "Impact of Covid-19 crisis on industrial production", available at: https://ec.europa. eu/eurostat/statistics-explained/index.php?title=Impact_of_Covid-19_crisis_on_industrial_ production.

Eurostat (2020b), "Impact of Covid-19 crisis on retail trade", available at: https://ec.europa.eu/eurostat/ statistics-explained/index.php?title=Impact_of_Covid-19_crisis_on_retail_trade.

Eurostat (2020c), "Impact of Covid-19 crisis on construction", available at: https://ec.europa.eu/ eurostat/statistics-explained/index.php?title=Impact_of_Covid-19_crisis_on_construction.

Eurostat (2020d), "Impact of Covid-19 crisis on services", available at: https://ec.europa.eu/eurostat/ statistics-explained/index.php?title=Impact_of_Covid-19_crisis_on_services.

Express Scripts (2020), “America's state of Mind report”, available at: https://www.express-scripts. $\mathrm{com} /$ corporate/americas-state-of-mind-report.

Frazier, M.L., Fainshmidt, S., Klinger, R.L., Pezeshkan, A. and Vracheva, V. (2017), "Psychological safety: a meta-analytic review and extension”, Personnel Psychology, Vol. 70, pp. 113-165.

Gautam, R. and Sharma, M. (2020), "2019-nCoV Pandemic: a disruptive and stressful atmosphere for Indian academic fraternity”, Brain, Behavior, and Immunity, Vol. 88, pp. 948-949.

Gavidia, M. (2020), "How has COVID-19 affected mental health, severity of stress among employees?", available at: https://www.ajmc.com/newsroom/how-has-covid19-affected-mental-healthseverity-of-stress-among-employees. 
ER

44,7
George, E. and Zakkariya, K.A. (2015), "Job related stress and job satisfaction: a comparative study among bank employees", Journal of Management Development, Vol. 34 No. 3, pp. 316-329.

Giorgi, G., Lecca, L.I., Alessio, F., Finstad, G.L., Bondanini, G., Lulli, L.G., Arcangeli, G. and Mucci, N. (2020), "COVID-19 related mental health effects in the workplace: a narrative review", International Journal of Environmental Research and Public Health, Vol. 17 No. 21, pp. 1-14.

Global Economic Prospects (2020), "Pandemic, recession: the global economy in crisis", available at: https://www.worldbank.org/en/publication/global-economic-prospects.

Hair, J.F., Black, W.C., Babin, B.J. and Anderson, R.E. (2010), Multivariate Data Analysis, 7th ed., Prentice-Hall International, New Jersey.

Hamouche, S. (2020), "COVID-19 and employees' mental health: stressors, moderators and agenda for organisational actions", Emerald Open Research, Vol. 2 No. 15, pp. 1-16.

Haque, A. (2021), "The COVID-19 pandemic and the role of responsible leadership in health care: thinking beyond employee well-being and organisational sustainability", Leadership in Health Services, pp. $52-68$.

Hayes, M. and Curran, L.P. (2020), "COVID-19 and work related stress: managing mental health of remote workers", available at: https:/www.lexology.com/library/detail.aspx?g=a9681162-aa65414f-b50f-dfc992a512b0.

Hayes, S.W., Priestley, J.L., Iishmakhametov, N. and Ray, H.E. (2021), "Stress and work-related burnout during Covid-19", available at: https://psyarxiv.com/vnkwa/download/?format=pdf.

Husain, S.F., Tang, T.-B., Yu, R., Tam, W.W., Tran, B., Quek, T.T., Hwang, S.H., Chang, C.W., Ho, C.S. and Ho, R.C. (2020), "Cortical haemodynamic response measured by functional near infrared spectroscopy during a verbal fluency task in patients with major depression and borderline personality disorder", EBioMedicine, Vol. 51, pp. 1-8.

Iavicoli, S., Leka, S. and Nielsen, K. (2020), "Promoting occupational health psychology through professional bodies: the role of the European academy of occupational health psychology", Work and Stress, Vol. 34 No. 3, pp. 215-218.

Ilmarinen, J. (2006), "Towards a longer worklife! Ageing and the quality of worklife in the European Union", available at: www.sopol.at/document/download/towards-a-longer-worklife.

Institute for employment studies (2020), "IES working at home wellbeing survey", available at: https:// www.employment-studies.co.uk/resource/ies-working-home-wellbeing-survey.

Institute of Macroeconomic Analysis and Development (2020), COVID-19 Scenario, UMAR, Ljubljana.

International Labour Organization. (2020a), "An employers' guide on working from home in response to the outbreak of COVID-19", available at: https://www.ilo.org/wcmsp5/groups/public/—ed_ dialogue/—act_emp/documents/publication/wcms_745024.pdf.

International Labour Organization (2020b), Managing Work-Related Psychosocial Risks during the COVID-19 Pandemic, ILO, Geneva.

Joo, B.K. and Lee, I. (2017), "Workplace happiness: work engagement, career satisfaction and subjective well-being", Evidence-Based HRM: A Global Forum for Empirical Scholarship, Vol. 5 No. 2, pp. 206-221.

Kabadayi, S., O'Connor, G.E. and Tuzovic, S. (2020). Viewpoint: the impact of coronavirus on service ecosystems as service mega-disruptions, Journal of Services Marketing, pp. 809-817, doi: 10. 1108/JSM-03-2020-0090.

Kaiser, H.F. (1974), “An index of factorial simplicity”, Psychometrika, Vol. 39 No. 1, pp. 31-36.

Kaushik, M. and Guleria, N. (2020), "Employee relations and engagement during Covid-19", Sparkling International Journal of Multidisciplinary Research Studies, Vol. 3 No. 2, pp. 1-11.

Khoreva, V. and Wechtler, H. (2018), "HR practices and employee performance: the mediating role of well-being", Employee Relations, Vol. 40 No. 2, pp. 227-243. 
Kihara, L.N. and Mugambi, H. (2018), 'Effect of stress management strategies on employees' performance in the public service", The Strategic Journal of Business and Change Management, Vol. 5 No. 2, pp. 2383-2405.

Kraus, S., Clauss, T., Breier, M., Gast, J., Zardini, A. and Tiberius, V. (2020), "The economics of COVID-19: initial empirical evidence on how family firms in five European countries cope with the corona crisis", International Journal of Entrepreneurial Behavior and Research, Vol. 26 No. 5, pp. 1067-1092.

Kundu, S.C. and Lata, K. (2017), "Effects of supportive work environment on employee retention: mediating role of organizational engagement", International Journal of Organizational Analysis, Vol. 25 No. 4, pp. 703-722.

Lee, H. (2021), "Changes in workplace practices during the COVID-19 pandemic: the roles of emotion, psychological safety and organisation support", Journal of Organizational Effectiveness: People and Performance, pp. 97-128.

Leite, H., Gruber, T. and Hodgkinson, I.R. (2020), "Flattening the infection curve - understanding the role of Telehealth in managing COVID-19", Leadership in Health Services, Vol. 33 No. 2, pp. 221-226.

Magnavita, N., Tripepi, G. and Di Prinzio, R.R. (2020), "Symptoms in health care workers during the COVID-19 epidemic. A cross-sectional survey", International Journal of Environmental Research and Public Health, Vol. 17 No. 14, pp. 1-15.

Management Events (2020), "The impact of COVID-19 on businesses", available at: https:// managementevents.com/news/the-impact-of-covid-19-on-businesses/.

Maslach, C. and Leiter, M.P. (2016), "Understanding the burnout experience: recent research and its implications for psychiatry”, World Psychiatry, Vol. 15 No. 2, pp. 103-11.

Maslach, C., Schaufeli, W.B. and Leiter, M.P. (2001), "Job burnout", Annual Review of Psychology, Vol. 52 No. 1, pp. 397-422.

Meyer, B., Zill, A., Dilba, D., Gerlach, R. and Schumann, S. (2021), "Employee psychological well-being during the COVID-19 pandemic in Germany: a longitudinal study of demands, resources, and exhaustion", available at: https://onlinelibrary.wiley.com/doi/10.1002/ijop.12743.

Mosadeghrad, A.M. (2014), "Occupational stress and its consequences: implications for health policy and management”, Leadership in Health Services, Vol. 27 No. 3, pp. 224-239.

Mousa, M., Massoud, H.K. and Ayoubi, R.M. (2020), "Gender, diversity management perceptions, workplace happiness and organisational citizenship behaviour", Employee Relations, Vol. 42 No. 6, pp. 1249-1269.

Mxenge, S.V., Dywili, M. and Bazana, S. (2014), “Organisational stress and employees' intention to quit amongst administrative personnel at the university of Fort Hare, Eastern Cape, South Africa", International Journal of Research in Social Sciences, Vol. 4 No. 5, pp. 13-29.

Oakman, J., Kinsman, N., Stuckey, R., Graham, M. and Weale, V. (2020), “A rapid review of mental and physical health effects of working at home: how do we optimise health?”, BMC Public Health, Vol. 20, pp. 1-13.

Qiu, J.-Y., Zhou, D.-S., Liu, J. and Yuan, T.-F. (2020), "Mental wellness system for COVID-19, brain, behavior, and immunity", available at: https://covid-19.conacyt.mx/jspui/bitstream/1000/3606/1/ 1104708.pdf.

Rahimnia, F. and Sharifirad, M. (2015), "Authentic leadership and employee well-being: the mediating role of attachment insecurity", Journal of Business Ethics, Vol. 132 No. 2, pp. 363-377.

Richardson, K.M. (2017), "Managing employee stress and wellness in the new millennium”, Journal of Occupational Health Psychology, Vol. 22 No. 3, pp. 423-428.

Rožman, M., Grinkevich, A.M. and Tominc, P. (2019), "Occupational stress, symptoms of burnout in the workplace and work satisfaction of the age-diverse employees", Organizacija, Vol. 52 No. 1, pp. $46-60$. 
ER

44,7
Schoot, B. (2020), "Working from home", available at: https://www.bloomberg.com/opinion/articles/ 2020-07-27/back-pain-insomnia-and-headaches-worsen-while-working-from-home.

Seidler, A., Thinschmidt, M., Deckert, S., Then, F., Hegewald, J., Nieuwenhuijsen, K. and Riedel-Heller, S.G. (2014), "The role of psychosocial working conditions on burnout and its core component emotional exhaustion-a systematic review", Journal of Occupational Medicine and Toxicology, Vol. 9 No. 1, pp. 1-10.

Shareena, P. and Mahammad, S. (2020), "Work from home during COVID-19: employees perception and experiences", available at: https://www.researchgate.net/publication/341459773_Work_ from_home_during_COVID-19_Employees_perception_and_experiences/citations.

Shinbrot, X., Wilkins, K., Gretzel, U. and Bowser, G. (2019), "Unlocking women's sustainability leadership potential: perceptions of contributions and challenges for women in sustainable development”, World Development, Vol. 119, pp. 120-132.

Singh, B., Shaffer, M.A. and Selvarajan, T.T. (2017), "Antecedents of organizational and community embeddedness: the roles of support, psychological safety, and need to belong", Journal of Organizational Behavior, Vol. 39, pp. 339-354.

Srivastava, S. and Agarwal, S. (2020), "Workplace bullying and intention to leave: a moderated mediation model of emotional exhaustion and supervisory support", Employee Relations, Vol. 42 No. 6, pp. 1547-1563.

Stein, M., B. (2020), "Coronavirus disease 2019 (COVID-19): psychiatric illness”, available at: https:// www.uptodate.com/contents/coronavirus-disease-2019-covid-19-psychiatric-illness.

Tabachnick, B.G. and Fidell, L.S. (2013), Using Multivariate Statistics, 6th ed., Pearson Education, Boston.

Tam, L. (2020), "Mental health and working from home: what companies can do to help staff amid prolonged Covid-19 disruption", available at: https://www.scmp.com/lifestyle/health-wellness/ article/3097606/mental-health-and-working-home-what-companies-can-do-help.

Tan, W., Hao, F., McIntyre, R.S., Jiang, L., Jiang, X., Zhang, L., Zhao, X., Zou, Y., Hu, Y., Luo, X., Zhang, Z., Lai, A., Ho, R., Tran, B., Ho, C. and Tam, W. (2020), "Is returning to work during the COVID-19 pandemic stressful? A study on immediate mental health status and psychoneuroimmunity prevention measures of Chinese workforce", Brain, Behavior, and Immunity, Vol. 87, pp. 84-92.

Wang, C., Pan, R., Wan, X., Tan, Y., Xu, L., Ho, C.S. and Ho, R.C. (2020), "Immediate psychological responses and associated factors during the initial stage of the 2019 coronavirus disease (COVID-19) epidemic among the general population in China", International Journal of Environmental Research and Public Health, Vol. 17 No. 5, pp. 1-25.

WHO (2020a), "Novel coronavirus (2019-nCoV) SITUATION REPORT - 1", Nover Coronavirus: World Health Organisation, World Health Organization, Geneva.

WHO (2020b), "Looking after our mental health", available at: https://www.who.int/campaigns/ connecting-the-world-to-combat-coronavirus/healthyathome/healthyathome-mental-health? gclid=CjwKCAjw88v3BRBFEiwApwLevWGYv3E7-Edoi19BOJW0iCR11k4fk2X_CgF2X_ Nmtz9bjzyaBgIjJRoC2z0QAvD_BwE.

Wong, B., Anderson, J., Greenwood, K., Krol, N., Nick Tzitzon, Vivek Bapat, Mike Maughan and Mac Keyser (2019), "Mental health at work", available at: https://umtclasp.com/wp-content/uploads/ 2019/10/Mind-Share-Partners-2019-Mental-Health-at-Work-Report-May-2019.pdf.

World Health Organization (2005), Mental Health Policies and Programmes in the Workplace, World Health Organization, Geneva.

Wu, Y., Xu, X., Chen, Z., Duan, J., Hashimoto, K., Yang, L., Liu, C. and Yang, C. (2020), "Nervous system involvement after infection with COVID-19 and other coronaviruses", Brain, Behavior, and Immunity, Vol. 87, pp. 18-22.

Zhang, X., Lin, Z., Liu, Y., Chen, X. and Liu, D.M. (2020), "How do human resource management practices affect employee well-being? A mediated moderation model", Employee Relations, Vol. 42 No. 4, pp. 903-919. 


\section{Further reading}

Jacobs, E. (2020), "Homeworking: isolation, anxiety and burnout", available at: https://www.ft.com/ content/315095c0-7da0-11ea-8fdb-7ec06edeef84.

Kim, S.W. and Su, K.P. (2020), "Using psychoneuroimmunity against COVID-19”, Brain, Behavior, and Immunity, Vol. 87, pp. 4-5.

Corresponding author

Maja Rožman can be contacted at: maja.rozman1@um.si

For instructions on how to order reprints of this article, please visit our website:

www.emeraldgrouppublishing.com/licensing/reprints.htm

Or contact us for further details: permissions@emeraldinsight.com 